\title{
The Potential of Adventure Game as a Media to Visualize Waste Disposal as Environmental Problems
}

\section{Study case: The Silent Age, Machinarium, The Inner World}

\author{
Luh Tassya Nindyapratama $^{1 *}$, Hafiz Aziz Ahmad ${ }^{2}$
}

\author{
${ }^{1}$ Institut Teknologi Bandung, Indonesia \\ ${ }^{2}$ Institut Teknologi Bandung, Indonesia \\ *Corresponding author.Email: tassyanindyapratama.ltn@gmail.com
}

\begin{abstract}
This research aims to identify the potential of utilizing adventure games to emphasize the waste disposal as environmental problems through the use of visual elements. Adventure game is one of the popular game genres that is known for its 'open world' system that allows players to explore every inch of the world space that is presented in that game. This makes every detail of the objects that were put in that world space determine what kind of mood and environment that the designer wants the player to see and interact with. The interaction between the player and the game world in the adventure game is also believed to be strong. Therefore, the visualization of the world that the designer presents in the game will be an important aspect that ensures the success rate of the gameplay. There are three adventure games with waste disposal aspects that are studied in this research: The Silent Age, Machinarium, and The Inner World. The visual elements of these three games will be analyzed through the A-E-I-O-U (Activity, Environment, Interaction, Object, and User) method framework. The goal of using this framework is to analyze data easier, while mapping and finding the significant relationship and interactions between categories inside the games. The result of this research shows that adventure games have the potential to visualize environmental problems by the world building aspect within the adventure game. By providing a visualization of environmental problems in the game, it is argued that players will develop interest in the environmental problems through game interaction. The result of this research hopefully could be useful information for future game designers in order to create better creative media that can improve people's awareness of the environmental problems that we all had.
\end{abstract}

Keywords: Adventure game, Game design, World building, Game visual 


\section{INTRODUCTION}

The popularity and needs from the wider community in various ages for video games are increasing in this pandemic COVID-19 era. Both smartphone and PC video games are significantly increasing on various game application services such as play store, steam, and so on. This hype unconsciously causes video games to become a daily activity in society as both medium of entertainment and media to obtain a certain information.

Video games are one of the most effective mediums to convey information because of the nostalgic effect from the interactions that we do while playing the game [1]. In adventure games, especially, the main key of the gameplay mechanic lies in the interaction between the player and the world in the game. The longer the player plays an adventure game, the more interaction the player has with the world and objects presented in the game. This concept is considered potentially great to make adventure games as a medium to visualize waste disposal as an object in the game, that players can interact with, throughout the gameplay.

Waste disposal itself is taken as a topic in this research, because it still has become one of the biggest environmental damage problems in Indonesia, which has become more problematic during this COVID-19 era. Based on data from CNBC Indonesia, the number of waste disposal, especially plastic, increased by $62 \%$ due to plastic wrap and bubble wrap used in package delivery services during the pandemic [2]. Indonesia is still considered not skilled enough to manage their own country's waste management properly. While 7000 tons of waste per day goes to the garbage dump (TPA), only about 100 tons of waste can be processed and sorted by scavengers per day [3]. The remaining waste has to be buried into piles of garbage in various landfills in Indonesia. This mountain of garbage is not only found in landfills, but in the oceans and various river estuaries in Indonesia. Between all this waste, plastic waste still dominates with a number of 46-57\%, and during this pandemic, PPE (Personal Protection Equipment) waste was also found in rivers for around $15-16 \%$ or equivalent to 0.13 tons per day [4].

From the previous data, it can be concluded that there is still a lot of waste that is being piled up in the environmental area and the lack of community empathy through this fact. There are many kinds of various media that have been used to provide awareness to the public about this waste problem, and this research is done to bring up the potential of what adventure games had as a media to bring this topic through the public. More in-depth study on this topic is needed, therefore, in this study, researcher will analyze the potential of adventure games as a medium to visualize the disposal of waste that occurs in the environment, as a form of realization of the environmental damage that is currently happening, to raise awareness for players who played the game.

\section{RESEARCH METHOD}

The data collected in this research will be studied descriptively qualitatively. All the data are obtained from the study of articles, literature, and a comparison will be made of three examples of similar game cases of the adventure game genre that had visualization elements of an environment waste inside the game, as research materials. The three games that will be studied are The Silent Age, Machinarium, and The Inner World. These three games were chosen based on the environmental theme and visualization that these three games had. Comparative analysis of similar games will be carried out using the framework method of A-E-I-O$\mathrm{U}$ (Activity, Environment, Interaction, Object, and User).

A-E-I-O-U is one of the Design Thinking Framework developed by Rick Robinson that guides designers to solve the problem by mapping the scenario from the following perspectives: activities, environments, interactions, objects, and users. This framework is usually used in organizing thoughts, observations, and also for usability testing [5]. This A-E-I-O-U framework method is also used by Kurniawan and Muljosumarto in their research to analyze color visuals in post-apocalyptic games, where this method is considered great at sorting and describing situations in order to achieve a faster solution [6].

The A-E-I-O-U framework stands for 5 categories to be observed. Based on the Design-Led Research Toolkit that Winnie Chang wrote, each category was defined like this: [7]

- Activities: includes actions with specific goals, and the process performed to achieve them.

- Environments: details the context and characteristic of the space where activities are being observed.

- Interactions: includes both impersonal and person-artifact interactions. 
- Objects: catalogues the items within the environment and how they are used.

- Users: includes the people within the environment that are being observed.

In this case of research, this framework is used to mapping the more detailed information about activities, visual elements, and interactions that can be found in the games, so that it can be easier to study and analyze both similarities and differences that these three games had.

\section{INTERACTION THEORY IN ADVENTURE GAME MECHANIC}

Adventure Game is a genre of game that is generally centered on the storyline of a character in the game. The goal of the player during the gameplay is to carry out certain missions, in order to solve the obstacles that are faced by the protagonist in the game. The game mechanic of this adventure game is related to the interaction between the player and the world formed in the game. Simulation in adventure games occurs when players interact with the world in the game [8].

The "world" is a very important aspect in adventure games. It is through this world that both the storyline and the space in the game are presented to the player. For example, the representation of the world presented in The Secret of Monkey Island game, which has a theme and characters who live as pirates, looks different from the game Ace Attorney: Miles Edgeworth, which has a theme and characters who live as prosecutors. This is due to the different approach that both of the games want to show the player. Each object displayed in the game, has been adjusted to the theme that the designer wants the player to feel.

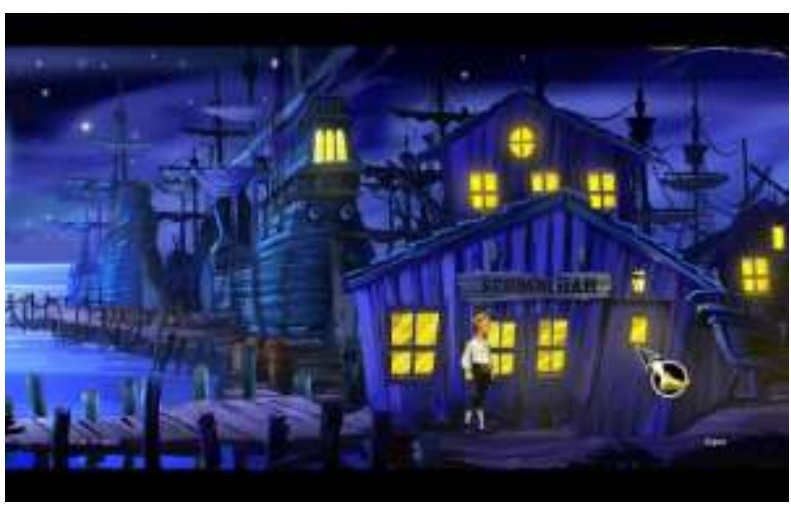

Figure 1 The Secret of Monkey Island game screen [mobygames.com, 2016]

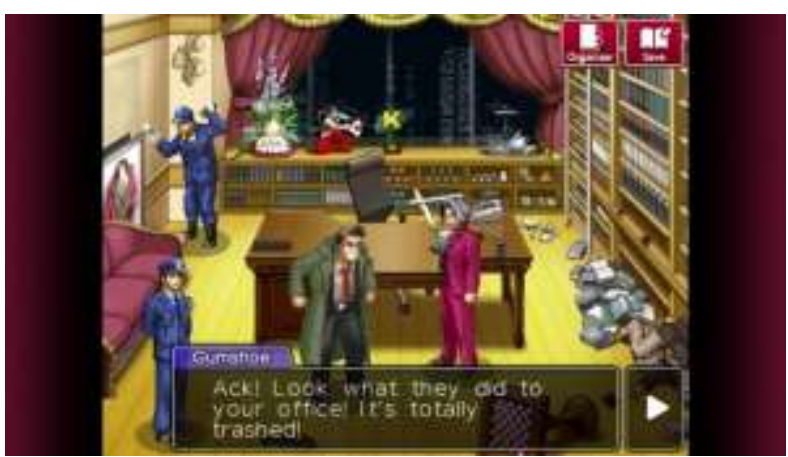

Figure 2 Ace Attorney: Miles Edgeworth game screen [toucharcade.com, 2017]

The representation or visualization of the world in the game is the first thing that the players see when they start to play an adventure game. Therefore, it becomes an important key for the designer to be aware of. Players must be able to guess and feel the theme of the game that will be presented, just by looking through the visual world that is being presented to them [9]. Usually, in the intro of adventure games, players are given the opportunity to explore the world, interact with nonplayer characters (NPCs) and objects in the world.

Through this interaction with the world and objects in the game, players are then presented with challenges to complete certain puzzles in order to continue the gameplay. This puzzle mechanic system is one of the methods that adventure games have, to indirectly provide a storyline to the players through some challenges [9]. Puzzles that are usually found in adventure games are looking for a way out, looking for hidden items, cracking codes, finding the correct answer, and so on.

\section{ANALYSIS OF VISUAL ELEMENTS IN ADVENTURE GAMES}

\subsection{Visual Overview and Game Theme}

Adventure games that have strong interactions with their environment are mostly found in the form of point and click games, where players have the freedom to control the movement navigation of the characters in the game, either by using the navigation button, or by pressing the location / object they want to interact with. The following are three examples of point and click adventure games that are considered to have the theme and visualization representation of environmental waste that this research brings up.

The first game is a game called "The Silent Age" which can be downloaded for free for iOS and android platforms. This game storyline is about a 
janitor who finds a time machine tool that he can use to save the world. The world setting in this game is separated into two timelines. The current time is shown as a world in the 1970s, and the future time is shown as the post-apocalyptic world that is being visualized as a world with many damaged objects and wild plants scattered around that world. Players are given the freedom to explore both of the periods, in order to solve the puzzles given through the gameplay. The players can also have a dialogue with NPCs, and enjoy the visual changes of both periods that are clearly presented in the game.

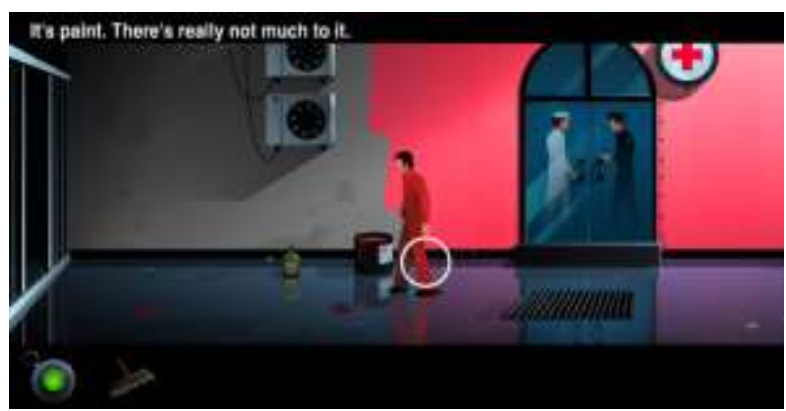

Figure 3 The Silent Age game screen 'present time'

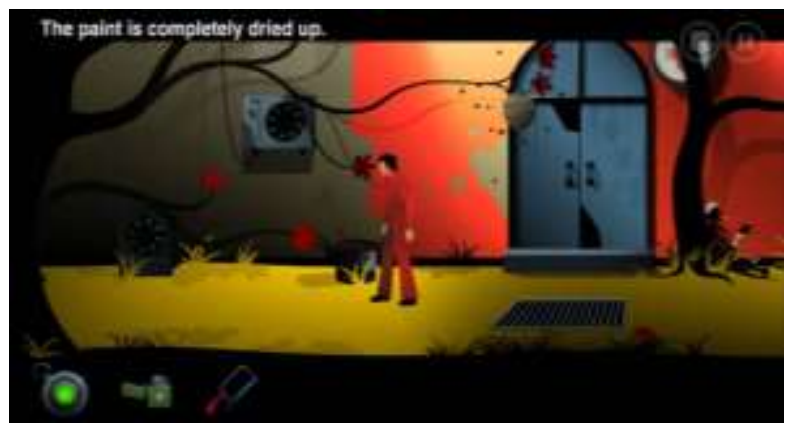

Figure 4 The Silent Age game screen 'postapocalyptic time'

The second game is a game called "Machinarium" that is available for both iOS and android platforms. This game offers a different approach to the players, as there is no dialogue given to players in this game. Players are given a challenge to figure out the task and gameplay through the interaction they do with the objects that are presented in the game. They also need to understand the storyline by themselves as they keep solving the puzzles given. Players will play the character of a robot, who is on a journey to save his lover. The visual appearance of this game is very detail oriented, and also won the best visual art award at IGF(Independent Games Festival) in 2009. The representation of dry plants, the brownish monochrome colors this game has, and the visual elements of the objects which are mostly metal, make the world in this game look very desolate and suffocating.

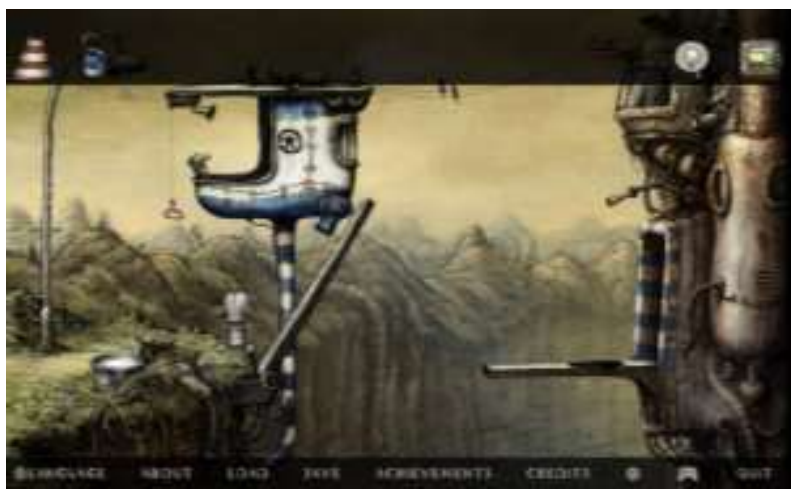

Figure 5 The Machinarium game screen

The third game is a game called "The Inner World" which can be found on PC, Mac and android platforms. This game has a storyline about a fantasy character named Robert, who lives with other citizens in the underground world, and goes on an adventure with a thief named Laura, to find out the truth about the world they already live in. The Inner World presents some animated interludes in the middle of the game, which is very entertaining for the players. The world setting that is formed in this game is an underground city. The color tone used in this game tends to be gloomy and monochromatic brown, like the Machinarium game that was already discussed earlier. Many dry plants and metal waste visuals were found scattered throughout the game, as a representation of an unhealthy environmental situation. However, the cartoon visual style that is being used in this game, and the stupid behaviour that the characters in this game presents, brings the humorous and funny atmosphere that make this game enjoyable for all ages.

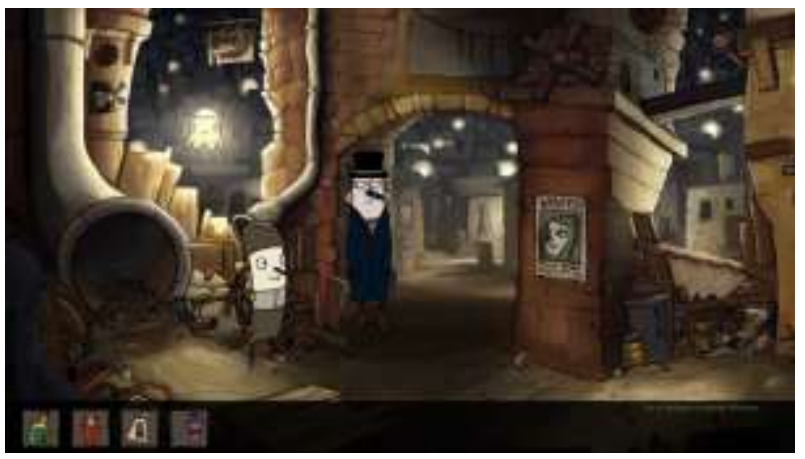

Figure 6 The Inner World game screen 


\subsection{Game Analysis Review Using A-E-I-O-U Framework Method}

The A-E-I-O-U method is a method which consists of Activity, Environment, Interaction, Object, and User. This method is used by the researcher to describe the activities, elements, and interactions of several adventure games that have been described in the previous point, to make it easier to study and analyze both similarities and differences for each category in the games.

From the description of the three tables bellow, there are four points that can be concluded, in how to show visualization of waste disposal that these three adventure games use. First, we can see that there are similarities in the activities category of the three games, which are the aspect of collecting objects and solving puzzles. Through this main activity, players have to think and grasp a better perspective of the game, to find which objects that they can interact and use within the gameplay. Therefore, it can be said that to get players aware of the situation that the games presents, an interactivity system is important to add, because interactivity in adventure games help players to observe the details. It can be seen that The Inner World game offers more interactivity in their game mechanics, as the player can take, observe and combine the objects in the game.

Second, is the connectivity between the visual and theme of the game. Observing the game environments is the main key for players to be able to carry out the challenges and the immersion of the story. Therefore, both environment and object categories should be connected to each other, as the written objects are obtained from the player's exploration of the world environment in the game. For example, in table 2, that is a statement that the environment that the player was presented in, was described as a 'city where the robot lives'. Therefore, the objects that the player can interact with in that area should represent the visualization of that image. The Machinarium game manages to show this representation, as the majority of objects the player can obtain in this 'city where the robot lives' are objects with iron and metal elements.

Third, is gaining empathy through the immersion of the story. To show and build player awareness of the environmental problems, we need to build empathy inside the players' feelings. And to do that, we need to build a world of immersion not only with visualization, but through a strong storyline also. Strong storyline in the game can persuade and make players feel many kinds of emotions and new perspectives that we want to give / show, which all these three adventure games already had inside the games. And lastly, it's about the importance of the details. Detailing the environments is really important to build the atmosphere in the game, that the game wants the player to feel throughout the gameplay, as all these three games have already succeeded. Display equations should be flush left and numbered consecutively, with equation numbers in parentheses and flush right. First, use the equation editor to create the equation. Then, select the equation, and set the "Equation" Style. Press the tab key and type the equation number in parentheses. 
Table 1. A-E-I-O-U Analysis: The Silent Age game-round 1

\begin{tabular}{|c|c|c|c|c|}
\hline Activities & Environment & Interactive & Object & User \\
\hline $\begin{array}{l}\text { Explore several different } \\
\text { places at once }\end{array}$ & Office Building & Observe the objects & Time machine & Players \\
\hline Collecting Objects & Police Station & Pick Objects & Iron Key & \\
\hline \multirow[t]{5}{*}{ Solve Puzzles } & Building Ruins & Walk & Handkerchief & \\
\hline & Wild trees & Running & Broom Handle & \\
\hline & Mountain of junks & Interact with NPC & Beater & \\
\hline & Basement & Unlocked locked doors & Rope & \\
\hline & & & Digital Card & \\
\hline
\end{tabular}

Table 2. A-E-I-O-U Analysis: Machinarium game-round 1

\begin{tabular}{|c|c|c|c|c|}
\hline Activities & Environment & Interactive & Object & User \\
\hline Collecting Objects & $\begin{array}{l}\text { City where the robot } \\
\text { lives }\end{array}$ & Pick Objects & Cans & Players \\
\hline \multirow[t]{6}{*}{ Solve Puzzles } & Metal house & Walk & Magnets & \\
\hline & Metal bridge & & Wire & \\
\hline & Mountain of junks & & Metal tools & \\
\hline & & & Spike & \\
\hline & & & Cable & \\
\hline & & & Light Bulb & \\
\hline
\end{tabular}

Table 3. A-E-I-O-U Analysis: The Inner World game-round 1

\begin{tabular}{|l|l|l|l|l|}
\hline \multicolumn{1}{|c|}{ Activities } & \multicolumn{1}{|c|}{ Environment } & \multicolumn{1}{c|}{ Object } & \multicolumn{1}{c|}{ User } \\
\hline Collecting Objects & Brick House & Observe the objects & Nets & Players \\
\hline Solve Puzzles & Underground City & Pick Objects & Glass Bottle & \\
\hline $\begin{array}{l}\text { Watching animated } \\
\text { interludes in the game }\end{array}$ & Mountain of junks & Combine objects & Doll & \\
\hline & & Walk & Bunning food & Caterpillars \\
\hline & & Interact with NPC & Twig & \\
\hline & & & Yarn & \\
\hline
\end{tabular}




\section{CONCLUSION}

Adventure games provide a strong storyline and many challenges that players can find through the interaction within the world that the game presents. The visualization of the world in adventure games is a very important aspect to give players a brief idea of the theme and atmosphere that the game wants players to feel throughout the gameplay. From the three examples of the games that have been compared, it can be concluded that there are differences in themes, visual styles, and storylines. However, all of these games can provide an overview of environmental damage and waste in different styles, through the presentation of certain objects such as barren plants, junks, and the use of monochrome brownish color tones for the visual theme. Players can notice all this detail indirectly through activities that players do in the game, which mostly collect and use those objects to solve the puzzles within.

When playing adventure games, players are required to be observed in order to complete the tasks given throughout the gameplay. Every detail in the world and the objects that are presented in the game is the main key of the gameplay, and therefore, being seen as one of the potential uses of adventure games as a medium to visualize and build player awareness of the danger that our environment has right now with waste disposal problems.

\section{REFERENCES}

[1] Madigan J. Getting Gamers: The Psychology of Video Games and Their Impact on the People who Play Them. Rowman \& Littlefield Publishers; United States; 2015.

[2] Gunung Limbah APD dan Sampah Plastik Hantui RI - CNBC Indonesia [internet]. [cited 2021 July 10]. Available from https://www.cnbcindonesia.com/news/ 20200728114800-4-175910/gunung-limbahapd-dan-sampah-plastik-hantui-ri

[3] Pengolahan TPST Bantargebang [internet]. [cited 2021 July 10]. Available from

https://www.beritasatu.com/megapolitan/72967 7/pengolahan-tpst-bantargebang-dinilai-makinbaik

[4] Cordova MR, Nurhati IS, Riani E, Nurhasanah, Iswari MY. Unprecedented plastic-made personal protective equipment (PPE) debris in river outlets into Jakarta Bay during COVID-19 pandemic, in: Chemosphere, 268, 2021.

[5] AEIOU Observation Framework [internet]. [cited 2021 July 19]. Available from https://openpracticelibrary.com/practice/aeiouobservation-framework/

[6] Kurniawan SD, Muljosumarto C. Analisis Visual Warna pada Game Post Apocalyptic, in: Jurnal Andharupa, 06 (01), 2020, p.18-31.

[7] Design-Led Research Toolkit AEIOU [internet]. [cited 2021 July 19]. Available from http://dlrtoolkit.com/aeiou/

[8] Fernandez VC. The Tribulations of Adventure Games: Integrating Story into Simulation through Performance, Ph. D. Georgia Institute of Technology, 2009.

[9] Wei H, Durango B. Exploring the Role of Narrative Puzzles in Game Storytelling. Paper presented at: DiGRA (Digital Games Research Association), in: Proceedings of the 2019 International Conference: Game, Play and the Emerging Ludo-Mix, 2019 Aug 06-10. 